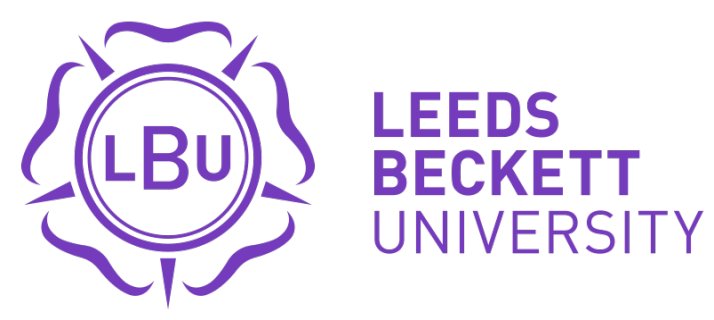

Citation:

Warwick-Booth, L and Coan, S and Bagnall, A-M (2019) Personalised housing support to improve health and well-being: findings from a local pilot programme in Yorkshire, England. Cities \& Health. DOI: https://doi.org/10.1080/23748834.2019.1644078

Link to Leeds Beckett Repository record:

https://eprints.leedsbeckett.ac.uk/id/eprint/6035/

Document Version:

Article (Accepted Version)

The aim of the Leeds Beckett Repository is to provide open access to our research, as required by funder policies and permitted by publishers and copyright law.

The Leeds Beckett repository holds a wide range of publications, each of which has been checked for copyright and the relevant embargo period has been applied by the Research Services team.

We operate on a standard take-down policy. If you are the author or publisher of an output and you would like it removed from the repository, please contact us and we will investigate on a case-by-case basis.

Each thesis in the repository has been cleared where necessary by the author for third party copyright. If you would like a thesis to be removed from the repository or believe there is an issue with copyright, please contact us on openaccess@leedsbeckett.ac.uk and we will investigate on a case-by-case basis. 


\title{
Personalised housing support to improve health and well-being: findings from a local pilot programme in Yorkshire, England
}

\author{
Authors \\ Louise Warwick-Booth*, PhD, MA, BA Reader, Leeds Beckett University, 519 Portland, \\ Portland Way, City Campus, Leeds, LS1 3HE Telephone 01138124341 *corresponding \\ author Orcid ID: 0000-0002-7501-6491
}

Susan Coan, BSc, Research Officer, Leeds Beckett University, 519 Portland, Portland Way, City Campus, Leeds, LS1 3HE Orcid ID: 0000- 0001-5279-8673

Anne-Marie Bagnall, PhD, BSc, Professor, Leeds Beckett University, 519 Portland, Portland Way, City Campus, Leeds LS1 3HE Orcid ID: 0000-0003-1512-0833

\section{*l.warwick-booth@leedsbeckett.ac.uk}

\begin{abstract}
The contribution that housing associations have made to public health in recent years is recognised within research and policy literature. This paper examines a partnership pilot intervention implemented by one housing association and one community healthcare service provider that aimed to improve the health and well-being of people with complex needs living in social housing stock in one area in England. The pilot delivered co-commissioned personalised support using a holistic model of care. This paper describes the pilot intervention and associated findings drawn from a mixed methods evaluation. The findings illustrate positive service user reports, including improved health and wellbeing, increased independence and reduced social isolation. The intervention was also associated with reduced use of community healthcare services; with an estimated potential local net saving of $£ 20,818$ during the year of the pilot. In conclusion, this small-scale pilot intervention supported clients with complex health needs whilst reducing demands on community health care services. Despite more research being needed in this area, particularly from larger and longer-term studies, this paper
\end{abstract}


contributes to the evidence base by illustrating an effective health and housing practice-based partnership approach.

\section{What is known about the topic?}

- Housing and health are interrelated; several aspects of housing can affect health and health service usage costs.

- Housing associations can make contributions to public health improvements in several ways.

- Policy documents suggest that joint working between health and housing services are a starting point for interventions which aim to deliver health improvements.

\section{What this paper adds}

- Analysis of a joint pilot intervention between health and housing services, which improved older people's health and well-being through the provision of targeted, individualised support.

- The views of service-users in relation to this model of care, including positive perceptions of better health, increased independence and reduced social isolation.

- Evidence related to potential cost savings: the pilot was associated with reduced use of community healthcare services; potentially saving $£ 20,818$ over a one year period.

\section{Key words}

Housing, health, housing and community care, evaluation, health service use, older people, social isolation, holistic approach 


\section{Introduction}

Cities are where most of the population lives; in the UK more than $80 \%$ of people live in urban areas (Naylor and Buck 2018) in which housing conditions vary significantly. Furthermore, the global population is ageing. The challenges of population ageing and urbanisation require policy attention, especially as service providers face additional challenges in trying to meet the needs of older people in a climate of austerity and associated budget restrictions (Steels 2015). Healthy housing is also important for achieving Sustainable Development Goal Eleven: making cities safer, inclusive and sustainable (UN 2016).

In public health terms, there is recognition that housing affects health in a myriad of ways (Shaw 2004), and adequate housing beyond just shelter, is a human right (OHCHR 2018, Bonnefoy et al 2003). Those who have the least resources often suffer the worst housing conditions (Bonnefoy 2007). Thus, housing is a social determinant of health (Marmot 2005, Marmot 2010, WHO 2017), shaping daily life, health and well-being (Baker et al 2014). Whilst the evidence base in this area has been methodologically problematic (Baker et al 2017), there are proven associations between housing and health in a range of areas (Pevalin et al 2008).

The existing literature illustrates that housing affects physical, social and mental health in addition to well-being via a range of direct and indirect pathways (Baker et al 2014, Bonnefoy 2007, Braubach et al 2011, Howden-Chapman 2002, Shaw 2004); including through internal housing conditions, area characteristics and housing tenure (Gibson et al 2011). Braubach et al (2011) note the environmental burden of disease linked to inadequate housing across eleven areas. Wider factors such as the neighbourhood, security of tenure and modifications for those with disabilities also affect well-being (Buck et al 2016, Parliamentary Office of Science and Technology 2011). Finance, access to health and care 
services, empowerment and relationships also determine physical, mental and social health in relation to housing conditions (Tweed 2017). Housing difficulties can also lead to stress and anxiety and have an impact upon other social determinants of health such as education and employment (Acevedo-Garcia 2000, Howden-Chapmen 2002).

Evidence also exists in relation to housing interventions and associated health outcomes. Several studies have illustrated positive associations between improvements to dwellings and health and well-being outcomes (Curl et al 2015, Bentley et al 2016). Multiple studies have explored the ways in which older people's health links to housing (Perez-Martin et al 2012), researching interventions aiming to support ageing in place. In later life, housing is increasingly important in ensuring quality of life and the ability to remain independent (Buggins et al 2012). Interventions are wide-ranging but tend to focus upon physical adaptations, assistance and the provision of home care assistance (Steel 2015, Buck et al 2016). Lui et al (2009) also argue that creating an enabling social context is as important as the physical environment in determining well-being in later life. The long-term care of older people should address their needs via a coordinated network of support, to ensure autonomous and active ageing (Ruppe 2011). In later life, housing is important in ensuring quality of life, and the ability to remain independent (Buggins et al 2012).

Policy-makers are increasingly aware of the links between housing and health. Since 2010, the WHO has been engaged in a process to develop Housing and Health Guidelines, in response to the growing evidence about the impact that housing has upon health (HowdenChapmen et al 2017). The WHO suggested eight key goals for housing to support health and well-being: provision of safety and security, sound construction, basic services (e.g. clean water), affordability, access to services, protection from climate change and reasonable security of tenure (Braubach 2011). In contrast, since the 1990s, English policy direction has focused upon the promotion of preventative strategies and the integration of services that aim 
to enable independence and self-care. The Five Year Forward View (NHS England et al, 2014), representing the national approach for English health care, encouraged efforts to deliver more healthcare outside of acute hospitals and closer to home (Monitor 2015). This approach aims to provide better care for patients, to reduce the number of unplanned bed days in hospitals and to bring down net costs. Braubach et al (2011) note the lack of evidence in relation to the health and cost benefits of housing interventions and call for more evaluation including shorter term studies. Keeping older patients in hospital when they cannot be discharged due to inadequate housing is estimated to cost the National Health Service (NHS) in England $£ 820$ million annually (National Audit Office 2016). Furthermore, it has been estimated that if policy makers could find $£ 10$ billion to improve the estimated 3.5 million 'poor' quality homes in England, this would save the NHS $£ 1.4$ billion in first year treatment costs alone (Nicol et al 2015). Thus, Public Health England (2015) launched a range of resources to enable partnership working with a focus upon improving health via housing, to potentially reduce more costly impacts upon wider health and social care services.

Housing associations in the UK provide social housing (equivalent to US public housing) in the form of rental properties on a subsidized basis for residents meeting pre-determined criteria. Usually thus includes the ability to afford housing (Fahey 1999). Previously housing associations have contributed to public health improvements through the provision of warm, affordable, energy efficient homes, care, and support services for tenants and via tackling financial issues. Many housing associations are experienced in delivering services and support to people experiencing social exclusion and health inequalities, and in working in partnership to deliver health improvement interventions (Buck et al 2016, National Housing Federation 2011). The need to tackle the social determinants of health within housing contexts requires collaborative partnership working (Windle 2015). There are now several examples of practice which demonstrate the need for joint working between housing and 
health services because of the multi-faceted relationship between housing and health (Tweed 2017). Buck and Gregory (2018) note that developing relationships locally in an area-based way is the key to improving the care of older people, with co-ordinated services across housing-led provision described as one way to reduce acute admissions. Again, such approaches fit with policy direction, indicating the need for strengths-based approaches which recognise the importance of community (Millar and Russell 2012), a focus upon local assets to build new models of care (Naylor and Charles 2018), local area coordination to deliver placed based systems of care (Ham and Alderwick 2015) and whole systems which integrate public health with housing (Sharpe et al 2018). Providing care closer to home is also discussed within policy-making literature (NHS England 2014). Housing providers are generally trusted by tenants, as they are well positioned to identify people who need additional support and able to implement early interventions to facilitate independence and better health (Family Mosaic 2016).

\section{Intervention and rationale}

This paper contributes to the growing evidence base on housing and health support by presenting findings from an evaluation of a pilot intervention delivered by one housing association (the voluntary sector based Connect Housing) in partnership with a community health service provider (Locala Community Partnerships CIC) in England. Connect Housing is a community benefit society, providing social housing and accompanying support to tenants as mechanisms to address inequalities, across one Yorkshire area. Locala Community Partnerships is an independent community interest company, providing NHS services to people within the same area. Both organisations contributed equal funding for the delivery and evaluation of the pilot programme. Their one-year pilot project (September 2015September 2016) aimed to improve the health and well-being of people with complex needs via the implementation of a new model of care (Realising the Value 2016). The premise of 
the pilot was that individualised assistance would support care closer to home as envisaged in English policy direction (Salisbury 2007, Ham et al 2012, Monitor 2015) increase service user independence and reduce health service usage costs.

Individuals living in a Connect Housing property with a long-term health condition or disability who were in receipt of care from community health teams (provided by Locala) were triaged as being at risk of needing increased levels of health care. A support worker contacted the identified residents and conducted an initial home visit to assess their needs across five key areas: economic well-being, home and housing, maintaining health and wellbeing, life skills and social isolation. One-to-one support tailored holistically to their individual needs was provided in the form of further home visits, follow-up telephone calls and signposting into other services, for example befriending schemes, luncheon clubs and social activity providers. By engaging in the life-worlds of residents (discussing their experiences, activities, and contacts), exploring their lived experiences and assessing the wider determinants of health impacting upon them, the support worker aimed to facilitate positive change across a range of health-related areas. In summary, the intervention was the provision of relational support for identified at-risk residents living in social housing properties.

\section{Overview of the pilot}

From September 2015 to September 2016, the support worker took 36 referrals and worked with a case load of 27 clients in total. 9 individuals who were referred were not supported, following on from their initial assessment. Some declined support, others did not engage with the worker or were assessed as being unsuitable based upon their levels of need (too high or too low) or their existing levels of support from other services. The project was established to work with individuals over the age of 50, with $75 \%$ of clients participating in 
the pilot aged 60 and over. In terms of the gender of the clients worked with during the pilot, there were slightly higher numbers of women (53\%). Most clients were white British (87\%), reflecting the area demographics. Referrals into the project were made by a range of health care staff (employed by Locala) with the largest number being from nurses (39\%) and community matrons (24\%). Referrals to other local agencies were diverse and included external agencies such as charities (Age UK, Citizens Advice), luncheon clubs, and some health care services, for instance the falls prevention and occupational therapy teams.

\section{Methods}

The evaluation utilised a mixed method approach, gathering qualitative data from semistructured interviews with stakeholders, service users and carers, and conducting statistical analysis of routinely collected monitoring and health service usage data. A mixed method design enabled the evaluation team to gain a better understanding of the issues than using either quantitative or qualitative research methods alone. Triangulating a range of data ensured broader exploration of the intervention and increased the validity and transferability of our findings (Robins et al 2008).

The evaluation aimed to explore the outcomes of the intervention for service users, how they valued the support worker, the use of multi-agency working and whether there were any reductions in health service usage. To achieve these aims, the research team developed a Theory of Change at the start of the evaluation (Judge and Bauld 2001) to make explicit the links between the programme goals and the different contexts and ways in which the project works (Figure 1). A Theory of Change is a specific methodology that enables researchers to clarify what is to be measured, agree evaluation questions and assess changes. The Theory of Change was used to test the mechanisms underpinning the intervention's proposed effects. We mapped the outcome measures and data collection tools to the Theory of Change, and 
tested the mechanisms by measuring the short, medium and longer term outcomes (where possible), to ascertain what worked and what did not.

\section{Figure 1 - Theory of Change (insert here)}

\section{Sampling and Recruitment}

The support worker delivering the pilot project advised the research team of participants to invite, providing a purposive sampling frame of relevant contacts. Participants were selected based on their involvement with the programme as staff, referrers or service users to offer insights as key informants. The service supported 27 clients over the year in which it was delivered, which served as the sampling frame for data collection with service users. The evaluation team made contact via email and telephone to ascertain willingness to participate, allowing participants time to decide. Thus, the sample for the qualitative component of the evaluation was self-selecting (see table 1 for full sample details).

\section{Table 1 sample characteristics (insert here)}

\section{Qualitative approach}

Semi-structured telephone interviews were conducted with stakeholders involved in delivering the service including the support worker $(n=5)$ and referrers $(n=5)$. The interview schedule covered the following areas: background to the project, the approach, changes occurring because of the project, the impact of the project on service users, and learning during project delivery. Interviews were conducted at the 6-month time-point of service delivery. Follow-up interviews $(n=3)$ at the 10-month time point captured further learning with key stakeholders still involved in the project delivery and able to participate.

Semi-structured interviews were also conducted with service users $(n=4)$ and a carer $(n=1)$. Those selected for interview were in good enough physical and mental health to discuss the 
service and how it had impacted upon their life, subjectively decided by the support worker because of her interactions with the client group, rather than via the use of a standardised assessment tool. The semi-structured interview schedule focused upon the self-reported impact of the pilot, exploring health, social support and general perceptions of the service (both positive and negative).

Feedback forms $(n=6)$ were designed and distributed by the support worker to capture experiences of what the service had offered clients, what worked well and their suggestions for improvements. These forms included free-text sections. These were used in cases where service users preferred not to be interviewed.

The verbatim transcripts from the interviews were analysed using framework analysis. Framework analysis develops a hierarchical thematic framework to classify and organise data according to key themes, concepts and emergent categories. The framework is the analytic tool that identifies key themes as a matrix where patterns and connections emerge across the data (Ritchie et al 2001). The matrix was drawn from the Theory of Change to deductively organise the data according to the aims of the evaluation. NVivo was used to collapse the data and then compare codes for similarities and differences. Themes were agreed by members of the evaluation team, following coding by SC.

\section{Quantitative approach}

Data on community health service use were received from Locala for all 27 clients. Service use data were available from $1^{\text {st }}$ April 2015 until $29^{\text {th }}$ August 2016. At the date of analysis (August 2016) 16 clients had been signed off from the service, with limited follow-up data being available for these clients. Dates of sign-off ranged from $7^{\text {th }}$ July 2015 to $10^{\text {th }}$ December 2015. 11 clients had not yet been signed off (i.e. were still using the service) and therefore no post-intervention follow-up data were available for these clients. Data on GP, 
Accident and Emergency, outpatient attendance and hospital admissions were available for 12 patients.

Quantitative health service usage data were cleaned and imported into SPSS for analysis. Descriptive statistics were generated, and non-parametric tests were used to compare clients' health service use over time (related samples Wilcoxon's signed rank test). Data were analysed on contact (face to face or telephone) with the integrated community care team (ICCT). The amount of direct clinical time before, during and after the intervention was compared and the estimated cost calculated using the PSSRU 2015 (PSSRU 2015) hourly rates for community nurses. The three time periods for the client group were:

- T0: before enrolment into the project (from $1^{\text {st }}$ April 2015 up to sign on date)

- T1: during enrolment in the project (between sign-on and sign off dates) and

- T2: after discharge from the project (from sign off date to $29^{\text {th }}$ August 2016).

The cost of the support worker for one year was then subtracted from the estimated potential savings to community healthcare due to reduced contact with health services.

\section{Research Ethics}

The evaluation was given ethical approval through Leeds Beckett University ethics procedures.

\section{Findings}

The framework analysis of the qualitative data showed several positive outcomes, including improved health and well-being, more independence and reduced social isolation. From the perspective of the service-users, the joint pilot had made a difference to their lives. There were also positive perceptions of the role of the support worker, including the time available to work with people, the flexibility associated with the role and its unique approach when 
compared to existing services. However, the data gathered also illustrated several challenges in the implementation of this project. These themes are presented below, with illustrative quotes.

\section{Positive outcomes for service users}

Several positive outcomes were self-reported by service users, including increased independence, decreased social isolation, better access to services, mental health improvements, increased confidence and improved well-being. The support worker enabled service users to develop independent living skills which in some instances resulted in them joining classes and gaining support from befrienders:

'Well I've only had one lesson, and he's learnt me how to go to [name of shop] to do me shopping online.' (Service User 3)

'...encouragement as to what I could do, you know, [...] more confidence to try things' (Service User 4)

'I used to get very depressed, well I don't get depressed now really you know. I mean there's times when I think about my husband [who passed away] and I get a bit depressed then, but it passes.' (Service User 1)

The support worker also enabled service users to become involved in community activities and arranged for visitors to see them at home. One service user commented,

I never went nowhere, I never saw nobody. And now I can go out, I can go to the lunch club and have my friend that comes and a young man comes to teach me 
computer. In fact, I've something happening more or less every day now, I see somebody and it's all because of her [the support worker]. '(Service User 1)

Service users reported increased well-being and confidence just from knowing that different social options were available, even if they chose not to take up the offer. The support worker's visits were described as having a positive effect on service users' mental health in terms of them feeling supported. Stakeholders involved in project delivery also recognised this:

'So, where there have been people referred by a district nurse or a community matron, they can see it does make a demonstrable difference to that patient's life, which helps in the person's life and in their health as well.' (Stakeholder 2 follow-up)

All the service users who completed a feedback form felt that the service had been explained to them, and helped with advice, information, and signposting very well. Most of the respondents also thought that it offered practical and emotional support very well. Regarding the specific support, the home visits were considered useful by all respondents. All respondents who received phone calls, signposting and emotional support also found those aspects of the service useful. The feedback forms mirrored the themes reported in the interview data. Several service users commented that the support worker was very reliable which contributed to them developing rapport with her. Service users appreciated the fact that the support worker had time to listen to them and wasn't in a hurry to get away:

'[Support worker] has time to listen, we never feel she's in a hurry, though she might be.' (Feedback Form 1)

One service user appreciated the support worker's advice and reported positive changes in relation to health: 
“Nothing has been too much trouble. Top marks [name of supportworker] @ Locala. Her help and advice has been extremely appreciated. I am housebound and have already stopped smoking and drinking' (Feedback Form 6)

The support worker was described several times as being supportive, kind and patient: 'I never felt 'judged' even when I was finding my circumstances extremely difficult to cope with.' (Feedback Form 3)

\section{Support worker role}

A number of key strengths of the support worker role were identified in the interview data. A significant benefit was the fact that the support worker could work with service users for as long as necessary, as recognised by those referring into the pilot:

'Some people we see just need a bit more ongoing support and support over time, and other services can sometimes go in and I don't know, support or advise but then perhaps can't continue or spend the same amount of time as it appears that the support worker would be able to do.' (Referrer 2)

The role also involved being flexible in terms of focus, support and delivery. The holistic focus of the role was identified as being of key importance with the service user dealt with as a whole person, rather than as a set of distinct problems. This involved including and working with family members where appropriate and with consent. One stakeholder said:

'I also think it's a success from the point of service users, because the remit's not restricted ...from their point of view they feel there's someone on their side and they're not just restricted to one area to discuss...I think it's quite unique, in that it's not time-limited, its remit's not limited, it's really flexible. It's a free service as well.' (Stakeholder 3 Follow Up) 


\section{Multi-agency working}

Stakeholder interview data provided insight into how the project operated within a multiagency context. The pilot was described as a different model of working compared to previous service offers, and the location of the support worker was important. The support worker role included joined up working with a range of other service providers and was a means of lightening the load of other health care professionals by acting as one point of referral and signposting:

'I think the main thing was trying to reduce the number of services that are going into the patient, and to make it sort of more efficient and effective...trying to reduce the overall workload with that patient, sort of trying to maybe get things under one umbrella with the different services... hopefully it would mean the patient's needs are being met more, so it's helping the work that you are doing with the patient anyway.' (Referrer 1)

The co-location of the support worker alongside healthcare professionals within a health centre was viewed as being highly beneficial. Referral processes were considered to be straightforward and less time-consuming than other service routes. Being able to discuss potential referrals with the support worker was a strength cited by all of the referrers interviewed:

'The support worker being visible and being in the meetings and being in the buildings, then it makes more sense because you can have a conversation as well as writing a paper referral.' (Referrer 5)

However, there were some issues identified in relation to referral processes. Raising awareness of the service upon its establishment was described as challenging and fewer referrals than expected were made. Ensuring the continued visibility of the service offer 
proved a challenge. Concerns were raised in relation to potential referrers being perceived as unwilling to refer into the service due to being over-burdened with work or unable to see the value of it:

'Well initially it was a challenge that the health service is made up of a broad range of professionals and actually getting all those different professional groups to understand what the service was, that was a key challenge initially.' (Stakeholder 1 Follow Up)

Referring out and signposting service users on was not seen as problematic: one referrer said: '...she's got all that background and I think straight away she understands and probably has a good idea of what would benefit the patient and what she can signpost to, you know, support groups out there.' (Referrer 4)

Working in a multi-agency setting posed some challenges, including lack of shared access to systems, which hindered information sharing and the tracking of service-users. Consequently, linking all care providers was an issue identified by some stakeholders:

'One challenge has been that I don't actually have access to SystmOne, that's the system that all the NHS's is on there... And it would help if everybody knew I was involved and I was going in, which at the moment is not the case.' (Stakeholder 4)

Understanding of the service offer amongst other professionals was on occasion incorrect:

'At the moment it's a Health and Well-being Pilot, but people see it as Connect Housing pilot...that can be misleading in terms of people thinking it's a housing project and understanding my remit.' (Stakeholder 4)

A final challenge that was noted in relation to the role was the limited capacity available (i.e. one part-time worker): 
'...so, there's a capacity, but I mean we all have that problem and she's just one person, so that's the only thing.' (Referrer 5)

Despite these issues, there was some evidence of improved communication between the health and housing sector, as demonstrated in referral patterns and reports of more joined up working. This was an intended outcome of the intervention in relation to strengthened partnerships and networks, which are essential in complex case management spanning health and social care.

\section{Change in health service use}

Data are presented for the average change in service use between time periods (T0-T1; T0T2; T1-T2). Change over time was first calculated for each client, then this was averaged across the group to give the figures presented in the last 3 columns in Table 1. Data were provided in the following categories:

Direct contact (all): this refers to direct contact face to face, by telephone or by video with the patient in a clinical context (e.g. not just to make a further appointment). Around $90 \%$ of such contacts are face to face.

ICCT direct contact: This refers to direct patient contact, in a clinical context, with the integrated community care team at Locala (this includes district nurses, community matrons and therapists).

ICCT direct clinical time: This refers to time spent by ICCT staff with the patient in a clinical context. 
ICCT total clinical time: This refers to time spent by ICCT staff on a patient, including writing up notes and consulting with other professionals.

SPC contacts: This refers to the number of calls made to a single point of contact call centre for each patient.

ICCT time per 4 weeks: This refers to time spent with the client by ICCT staff averaged over a 28 day period.

Statistically significant reductions $(\mathrm{p}<0.05)$ were seen between the time periods $\mathrm{T} 0$ and $\mathrm{T} 1$ for all community health service use outcomes, apart from ICCT time per 4 weeks. Smaller reductions were seen for all outcomes between the time periods $\mathrm{T} 0$ and $\mathrm{T} 2$, and these were statistically significant for the outcomes of direct contact (all), ICCT direct contact and SPC contacts, suggesting that the effects were maintained for these outcomes after the patients were discharged from the intervention.

No statistically significant differences were seen between the time periods T1 and T2 the intervention, which suggests no substantial drop-off in effect in the brief time period after discharge from the intervention.

Table 2 Aggregated community health care service use data (insert here) Data on GP, Accident and Emergency, outpatient attendance and hospital admissions were available for 12 patients. No statistically significant differences were seen between T0 and $\mathrm{T} 2$.

Table 3 Primary and secondary care service use data (insert here)

\section{Potential cost implications}


The data provided showed that ICCT direct clinical time before the intervention came to a total of 986.9 hours; during the intervention it was 295.4 hours, and after the intervention it was 304.3 hours. ICCT total clinical time before the intervention came to a total of 1181.1 hours; during the intervention it was 359.8 hours and after the intervention it was 347.7 hours.

Although several different types of health care professionals were involved in providing care, we have used Unit Costs of Health and Social Care (PSSRU 2015) hourly rates for community nurses of $£ 44$ per hour or $£ 58$ per hour of patient related work to estimate potential costs saved:

Direct clinical time saved (T0-T2): 691.5 hours $x £ 58$ per hour $=£ 40,107$ potential savings Indirect clinical time saved (T0-T2): $(821.3-691.5)=129.8$ hours $\mathrm{x} £ 44$ per hour $=$ $£ 5,711.20$ potential savings.

Total potential cost savings for community healthcare: $£ 45,818.20$

The support worker cost of $£ 25,000$ during the period September 2015-September 2016, for 20 hours per week was subtracted from the total estimated cost savings to give an estimated net saving of $£ 20,818.20$ over the year in which the pilot project ran. It is worth noting that the support worker spent a variable amount of time with each client based upon their level of need.

\section{Discussion}

The findings from our evaluation illustrate that providing social support for older residents living in urban social housing results in health and wellbeing improvements and reduced health care service costs. The findings contribute to the evidence base for age-friendly communities by highlighting the importance of holistic support for older people as a 
mechanism to build protective factors and resilience. Therefore, the data gathered validates the Theory of Change. Support from a worker who engaged with the life-worlds of clients (mechanisms for change), led to self-reported health improvements amongst service users as well as improved economic outcomes (lower costs for community healthcare). Expected organisational outcomes were achieved to some extent such as strengthened partnerships and innovation in local multi-agency practice (see figure 1).

In the data from the qualitative interviews, service users reported experiencing improvements in their own health (see long term outcomes in figure 1). This resonates with recent evidence in which the health of social housing tenants was improved as a result of tailored support (Buck et al 2016, Family Mosaic 2016). There is a clear case to be made for the importance of health and housing working together, because housing providers can positively impact upon health given their position in communities (Buck et al 2016, Tweed 2017). Allen (2007), reporting on the 'Housing for Healthier Hearts Project' in Bradford, West Yorkshire, found that the intervention, based upon a health worker offering advice, support and referrals, made a difference to the lives of the residents who engaged with it. Added value in the form of advice, support and advocacy was noted because residents were otherwise left alone after completion of any medical treatment. Whilst this intervention was aimed at a different client group (Southeast Asian community members experiencing chronic illness), Allen (2007) illustrated that a short-term task centred programme, delivered by housing and health staff can make a difference in mental health and quality of life. Thus, housing providers can implement initiatives to improve health for a range of service users (Tweed 2017).

Research also suggests the need for multi-professional help as a mechanism to support tenants to live well and independently in their own homes. Services offering resources and support (Steels 2015), prevention and re-enablement (Cook et al 2017) are important. Social support is central to health status, with Dunn (2000) noting that the home can serve as a base 
for social interaction and the provision of extra-local social support for both housing and health.

Key components of this pilot linked to prevention, were referrals into other services, alongside local social support, in the form of a holistic one to one service offer. Focusing upon a specific population and its needs, and co-designing care pathways is an important approach for those delivering a new model of care (Starling 2018).

Our evaluation findings indicate that the support worker role was highly valued by service users. Starling (2018) argues that change will only happen when workers have the right capabilities, and skills to deliver new models of care. Wider stakeholders referring into the project reported the value of the role in relation to encouraging care closer to home and service user independence. Evidence from systematic reviews show that self-management can be effective in reducing unplanned admissions for patients with numerous medical conditions (Purdy 2010). In the joint pilot it was evident that the support worker enabled service users to self-manage their conditions, thus achieving care closer to home as an outcome (again see figure 1). Other evidence relating to interventions delivered by housing associations (Bagnall et al 2016) shows notable improvements in several well-being categories, such as increased self-esteem and physical activity, as a result of similar support to that offered within this pilot. A support worker whose remit focuses upon holistic support is important in tackling the intermediate determinants of health such as access to other services, control and relationships (Tweed 2017). Outside of social housing, similar results have been reported in services using a social prescribing approach with participants aged (mean) 53.1 years. Well-being Co-ordinators enabled individuals to have a more positive and optimistic view of their life through offering opportunities to engage in a range of hobbies and activities in the local community (Woodall et al 2018). 
Policy argues that more joined up working is essential in complex case management spanning health and social care. This service model is an example of a joined-up approach, successfully implemented in an urban context, with local multiagency innovation and strengthened partnerships achieved as intermediate organisational outcomes (illustrated in figure 1). However, collaborative partnership working involves challenges. In this instance, concerns were reported about referrers based in the healthcare sector not recognising the value of the project, or mistakenly believing that the housing association only dealt with issues relating to the properties they manage, and therefore not sign-posting people into the intervention. Similar concerns have been reported in other housing intervention evaluations (Barker et al 2014, Bagnall et al 2016). This may in part be the result of different organisational approaches and structures resulting in implementation gaps, despite policy recognition that housing is an important way to improve older people's health (HowdenChapmen et al 2011). Buggins et al (2011) note the importance of organisations working together to address health needs and associated inequalities in individual homes, but do not offer analysis of the practical and logistical issues associated with such approaches in practice.

In terms of health service use, the literature illustrates how similar health and well-being interventions can reduce NHS usage for planned hospital appointments, although these conclusions were based upon self-reported data (Windle 2015, Family Mosaic 2016). Other authors have made a case for both the financial and social value of using preventative measures within communities as a mechanism to reduce costly emergency admissions (Blunt et al 2010, Buck et al 2016). Buck and Gregory (2013), in an impact assessment of two housing improvement programmes in Birmingham, England, found that for an outlay of $£ 12$ million, the local authority achieved savings of $£ 24$ million. Borgloh and Westerhide (2016) show that social worker support in four housing projects in Germany was linked to significant 
potential socioeconomic cost savings. The provision of more generalised support is similar to the model used within the intervention evaluated here. Despite this, our evaluation showed a reduction in use of some community-based health services and therefore associated cost savings, supporting existing evidence of improved economic outcomes in this area (Buck et al 2016). However, caution is required when examining health service usage data because a range of impact measures need to be documented (The Nuffield Trust 2013).

In summary, for older people who wish to age in place, the urban setting presents complex challenges in many contexts (Steels 2015). Our evaluation shows that multi-agency support targeted at social housing residents in one urban context led to improvements in health and reduced costs to associated services. Holistic support for health improvement linked specifically to housing type in urban contexts can facilitate care closer to home, and enable older people to live independently for longer. For policy-makers our evaluation illustrates that investment in holistic support focused upon social housing tenants, can improve health and reduce wider service costs.

\section{Strengths and Limitations}

The pilot project evaluated here adds to the evidence base by illustrating the positive impact that a joint intervention between health and housing can have in relation to health improvements for service users. Our qualitative data illustrates the importance of the targeted individualised and holistic support, which includes a relational element. By offering clients the chance to share their comments through the feedback forms in addition to the interviews, we captured the views of $11(41 \%)$ out of the total of 27 clients who were supported. We were also able to analyse service use data for individuals, which is often not accessible or supplied at a level which shows change. 
However, the pilot project only worked with a small number of participants for one year. The sample for the evaluation was therefore small. Service users uniformly reported positive outcomes, with no alternative and perhaps more critical voices captured. The service users who participated in the evaluation through interviews and feedback forms were mainly female, therefore potential gender differences were not explored. Stakeholders' perceptions were in the main positive but did also acknowledge some difficulties associated with referral processes.

The quantitative data obtained suggests that the pilot intervention resulted in reduced service use, with associated reductions in costs of NHS staff time, which could potentially lead to further savings if extrapolated to a larger number of clients. However, there were also limitations in relation to the health service data usage. There was missing data for some clients, which was therefore excluded from the analysis. There was limited length of followup and only 16 patients had been discharged at the point of analysis, so there was not enough data to judge whether the positive changes in terms of reduced service use seen during the intervention were maintained for all clients after they were discharged from the service. With longer follow-up (6-12 months after discharge) more reliable estimates about this could be made. The evaluation team were commissioned to explore the pilot intervention over its one year delivery period, and therefore were unable to access longer term data sets. Secondly, the GP, Accident and Emergency, outpatient and hospital admissions data were only available for 12 clients, limiting the scope of the analysis and further generalisability.

\section{Lessons for practice}

This intervention, like similar programmes, cost little to implement whilst offering a service with the client at the centre, supporting the delivery of holistic service provision (Yaxley 2015). Two particular lessons are of use to the implementation of other joined up pilot 
projects within health and social care. Firstly, there is a need for any support worker to have access to health systems as a single place where service user information can be both retrieved and recorded to better link together housing and health support and enable more efficient tracking. Secondly, there is a need for promotion of any co-commissioned service in both sectors (housing and health) with accompanying clarity about function and responsibility as an on-going aspect of the project delivery. Establishment of new service models takes time to implement, and staff from different areas therefore benefit from ongoing reminders.

\section{Conclusion}

Housing providers in partnership with community service providers have the potential to improve the health of those with long-term conditions alongside reducing local health care usage costs through the provision of care closer to home and a holistic service offer. This evaluation showed favourable service-user perceptions and experiences of a small-scale pilot intervention. There was also a reduction in usage of community health services and cost savings associated with this.

There is more work to be done in analysing the impact of projects such as this in terms of scaling up such an approach and assessing sustainability over a longer-period of time, as well as potential reductions in the usage of emergency services. Many jointly agreed developments between housing and health have been labour intensive, one-off approaches with time limited funding (LGA 2015), which poses evaluation challenges.

\section{References}

Allen, T. (2007) Private Sector Housing Improvement in the UK and the Chronically Ill: Implications for Collaborative Working Housing Studies 20,1, 63-80. 
Acevedo-Garcia, D. (2000) Residential segregations and the epidemiology of infectious diseases Social Science and Medicine 51, 1143-1161.

Bagnall, AM., Southby, K., South, J., \& Gamsu, M. (2016) Evidence Briefing Housing Associations and Housing Interventions: Delivering Community-Centred Approaches for Health and Well-Being Leeds Beckett University http://eprints.leedsbeckett.ac.uk/2966/

Baker, E., Mason, K., Bentley, R. \& Mallett, S. (2014) Exploring the bi-directional relationship between health and housing in Australia Urban Policy Research 32, 71-84.

Baker, E., Beer, A., Lesterm L., Pevalin, D., Whitehead, C. \& Bentley, R. (2017) Is housing a health insult? International Journal of Environmental Research and Public Health 14, 567 585.

Barker, S., Heaslip, V., \& Chelvanayagam, S. (2014) Addressing older people's mental health needs in the community setting British Journal of Community Nursing 19, 5, 234-8.

Bentley, R., Reeves, A. \& Baker, E. (2016) Housing: the hidden health intervention The Conversation October 21, 2016.

Blunt, L., Bardsley, M., \& Dixon, J. (2010) Trends in Emergency Admissions in England 2004-2009: Is greater efficiency breeding inefficiency? Nuffield Trust, London.

Bonnefoy, X, Braubach, M., Moissonnier, B., Monobaev, K. \& Robbel, N. (2003) Housing and health in Europe: preliminary results of a pan-European study American Journal Public Health 93, 1559-1563.

Bonnefoy, X. (2007) Inadequate housing and health: an overview International Journal of Environment and Pollution 30, 3/4, 411-429.

Borgloh, S. \& Westerhide, P. (2016) The Impact of Mutual Support Based Housing Projects on the Costs of Care Housing Studies 27, 5, 620-642. 
Braubach, M., Jacobs, D. \& Ormandy, D. (2011) Environmental burden of disease associated with inadequate housing. A method guide to the quantification of health effects of selected housing risks in the WHO European Region WHO, Geneva.

Buck, D., Simpson, M., \& Ross, S. (2016) The economics of housing and health. The role of housing associations Kings Fund available at https://www.kingsfund.org.uk/publications/economics-housing-health

Buck. D. \& Gregory, S. (2013) Improving the public's health: a resource for local authorities Kings Fund, London.

Buck. D. \& Gregory, S. (2018) Housing and Health. Opportunities for sustainability and transformation partnerships Kings Fund, London.

Buggins, E., Kaur, B. \& Handy, C. (2012) Shaping the concrete before it sets: Building effective health and housing partnerships - the leadership challenge Housing Learning and Improvement Network, London.

Cook, G., Bailey, C., Hodgson, P., Gray, J., Barron, E., McMillan, C., Marston, R., Binks, E., \& Rose, J. (2017) Older UK sheltered housing tenant's perceptions of well-being and their usage of hospital services Health and Social Care in the Community 25, 5, 1644-1654.

Curl, A., Kearns, A., Mason, P., Egan, M., Tannahil, C. \& Ellaway, A. (2015) Physical and mental health outcomes following housing improvements: Evidence from the GoWell Study Journal of Epidemiology and Community Health 69, 12-19.

Dunn, J.R. (2000) Housing and Health Inequalities: Review and Prospects for Research Housing Studies 15, 3, 341-366.

Fahey, T. (1999) Social Housing in Ireland. Dublin, Oak Tree Press. 
Family Mosaic (2016) Health Begins at Home Final Report (2016) available at http://www.familymosaic.co.uk/userfiles/Documents/Research_Reports/Health_final_report 2016.pdf

Gibson, M., Petticrew, M., Bambra, C., Sowden, A., Wright, E. \& Whitehead, M. (2011) Housing and health inequalities: a synthesis of systematic reviews of interventions aimed at different pathways linking housing and health Health and Place 17, 175-184.

Ham, C. \& Alderwick, H. (2015) Place-based systems of care. A way forward for the NHS in England Kings Fund, London.

Ham, C., Dixon, A. \& Brook, B. (2012) Transforming the Delivery of Health and Social Care: The Case for Fundamental Change Kings Fund, London.

Howden-Chapmen, P. (2002) Housing and inequalities in health J Epidemiol Community Health 56, 645-646.

Howden-Chapmen, P., Chandola, T., Stafford, M. \& Marmot, M. (2011) The effect of housing on the mental health of older people: the impact of lifetime housing history in Whitehall 11 BMC Public Health 11, 682.

Howden-Chapmen, P., Roebbel, N \& Chisholm, E. (2017) Setting Housing Standards to Improve Global Health International Journal of Environmental Research and Public Health 14,1542 .

Judge, K., \& Bauld, L. (2001) Strong theory, flexible methods: evaluating complex community-based initiatives. Critical Public Health 11, 19-38.

Local Government Association (LGA) (2015) A home is much more than a house. Integrated approaches for the housing, health and care needs of vulnerable adults LGA, London. 
Lui, C.W., Everingham, J.A., Warburton, J., Cuthill, M. and Barlett, H. (2009) What makes a community age-friendly: A review of international literature Australasian Journal on Ageing 28, 1164-1170.

Marmot, M. (2005) Social determinants of health inequalities Lancet 365, 1099-1104.

Marmot, M. (2010) Fair Society, Healthy Lives The Marmot Review, London.

Millar, L \& Russell, C. (2012) A Strength-based Approach to Ageing Well: the Housing

Dimension Housing Learning and Improving Network, London.

Monitor (2015) Moving healthcare closer to home available at

https://www.gov.uk/guidance/moving-healthcare-closer-to-home

National Audit Office (2016). Discharging older people from hospital available at https://www.nao.org.uk/wp-content/uploads/2015/12/Discharging-older-patients-from$\underline{\text { hospital.pdfn }}$

National Housing Federation (2011) Invest in Housing, Invest in Health available at http://www.housing.org.uk/resource-library/browse/invest-in-housing-invest-in-health

Naylor, C. \& Buck, C. (2018) The role of cities in improving population health. International insights. Kings Fund, London.

Naylor, C. \& Charles, A. (2018) Developing new models of care in the PACS vanguards. A new national approach to large scale change Kings Fund, London.

NHS England., Public Health England., Health Education England., Monitor., Care Quality Commission. \& NHS Trust Development Authority (2014) Five Year Forward View. http://www.england.nhs.uk/wp-content/uploads/2014/10/5yfv-web.pdf 
Nicol, S., Roys, M. \& Garrett, H. (2015) The cost of poor housing to the NHS Building Research Establishment Press.

OHCHR (2018) Article 11.1 of the International covenant on economic, social and cultural rights.

Parliamentary Offices of Science and Technology (2011) Housing and Health Postnote 371, available at http://www.parliament.uk/documents/post/postpn_371-housing health_h.pdf

Pevalin, D., Taylor, M.P. \& Todd, J. (2008) The dynamics of unhealthy housing in the UK: A panel data analysis Housing Studies 23, 5, 679-695.

Perez-Martin, A., Satue Bartolome, J.A., Gonzalo Pascua, S., Franco Moreno, A.I., Rodriguez Benavente, A. \& Zapatero Gaviria, A. (2012) Place of residence before hospital admission and mortality at 12-months in Spanish patients aged 70 years or older Geriatrics and Gerontology International 12, 695-702.

PSSRU (2015) http://www.pssru.ac.uk/project-pages/unit-costs/2015/

Public Health England (2015) New resources to improve health through the home https://www.gov.uk/government/news/new-resources-to-improve-health-through-the-home Purdy, S. (2010) Avoiding Hospital Admissions: What does the research evidence say? The King's Fund, https://www.kingsfund.org.uk/sites/files/kf/Avoiding-Hospital-Admissions$\underline{\text { Sarah-Purdy-December2010.pdf }}$

Realising the Value. Ten key actions to put people and communities at the heart of health and well-being (2016) available from www.realisingthevlaue.org.uk

Ritchie, J., Spencer, L., \& O’Connor, W. (2003) Carrying out qualitative analysis in Ritchie, J., \& Lewis, J. (Eds) Qualitative research practice: A Guide for Social Scientist Students and Researchers 219-262 London: Sage. 
Robins, C. S., Ware, N. C., dosReis, S., Willging, C. E., Chung, J. Y., \& Lewis-Fernández, R. (2008). Dialogues on mixed methods and mental health services research: Anticipating challenges, building solutions. Psychiatric Services, 59, 727-731.

Ruppe, G. (2011) Active Ageing and Prevention in the Context of Long Term Care. Rethinking Concepts and Practices European Centre Policy Brief.

Salisbury, C., \& Purdy, S. (2007) Providing care closer to home British Medical Journal 35, 335 doi: http://dx.doi.org/10.1136/bmj.39371.523171.80

Sharpe, R.A., Taylor, T., Fleming, L.E., Morrissey, K., Morris, G., \& Wigglesworth, R. (2018) Making the Case for 'Whole System' Approaches: Integrating Public Health and Housing international Journal of Environmental Research and Public Health 15, 2345; doi:10.3390/ijerph15112345.

Shaw, M. (2004) Housing and Public Health Annual Review of Public Health 25, 397-418

The Nuffield Trust (2013) Evaluating integrated and community-based care http://nuffield.dh.bytemark.co.uk/sites/files/nuffield/publication/evaluation_summary_final.p $\underline{\mathrm{df}}$

Starling, A. (2018) Implementing new models of care: lessons from the new care models programme in England International Journal of Care Co-ordination 21, 1-2, 50-54.

Steels, S. (2015) Key characteristics of age-friendly cities and communities: A review Cities $47,45-52$.

Tweed, E. (2017) Foundations for well-being: reconnecting public health and housing. A Practical Guide to Improving Health and Reducing Inequalities Scottish Public Health Network. 
UN (2016) Progress towards the Sustainable Development Goals: Report of the Secretary General USA, New York.

WHO (2017) Social Determinants of Health https://www.who.int/social_determinants/en/ Windle, K., Wagland, R., Forder, J., D’Amico, F., Janssen, D., \& Wistow, G. (2009) National Evaluation of Partnerships for Older People Projects Department of Health.

Windle, K. (2015) What role can local and national supportive services play in supporting independent and healthy living in individuals 65 and over? Future of an ageing population: evidence review Foresight, Government Office for Science.

Woodall, J., Trigwell, J., Bunyan, A., Raine, G., Eaton, V., Hancock,L., Cunningham, M., and Wilkinson, S. (2018) Understanding the effectiveness and mechanisms of a social prescribing service: a mixed method analysis BMC Health Services Research 18:604 https://doi.org/10.1186/s12913-018-3437-7.

Yaxley, N. (2015) Going round the houses. How can health and social housing professionals forge better links and what might the benefits be? Housing Learning and Improvement Network, London. 